TAP CHÍ KHOA HỌC ĐẠI HỌC TÂN TRÀO
ISSN: $2354-1431$

\title{
GIÁO DỤC PHÒNG TRÁNH VÀ ÚNG PHÓ VỚI LŨ QUÉT, SẠT LỞ ĐẤT CHO HỌC SINH TRUNG HỌC PHỔ THÔNG MIỀN NÚI BĂC BỘ - GIẢI PHÁP VÀ KINH NGHIỆM
}

\author{
Đỗ $V \tilde{u} \operatorname{Son}^{l *}$ \\ ${ }^{1}$ Khoa Địa lí, Truò̀ng Đại học Su phạm Thái Nguyên \\ *Email: sonvudo@gmail.com
}

\section{Thông tin bài viết}

Ngày nhận bài:

04/7/2020

Ngày duyệt đăng:

20/9/2020

Từ khóa:

phòng tránh và úng phó với lũ quét, sạt lở đất, day học tích hơp, day họ kết hơp, HS Trung học phổ thông, miền núi Bắc Bộ.

\begin{abstract}
Tóm tắt
Lũ quét, sạt lở đất ở miền núi Bắc bộ gây hậu quả ngày càng nghiêm trọng và khó lường. Việc nghiên cứu biện pháp hợp lý để giáo dục về phòng tránh và ứng phó với lũ quét, sạt lở đất cho học sinh miền núi là vô cùng cần thiết và cấp bách.

Tác giả đã sử dụng các phương pháp: tổng hợp và phân tích tài liệu, điều tra khảo sát thực tế, phương pháp chuyên gia, phương pháp dạy học kết hợp nhằm nghiên cứu khả năng và triển khai việc giáo dục ý thức bảo vệ môi trường, kỹ năng tự bảo vệ trước thảm họa thiên nhiên cho học sinh Trung học phổ thông miền núi, thông qua đó tuyên truyền sâu rộng ý thức, trách nhiệm bảo vệ môi trường tới xã hội. Những vấn đề rút ra từ quá trình nghiên cứu là kinh nghiệm quý báu cho việc tổ chức giáo dục cho học sinh ở các khu vực khác.
\end{abstract}

\section{1. ĐẠTT VẤN ĐỀ}

Miền núi Bắc bộ gồm 10 tỉnh: Hà Giang, Cao Bằng, Lào Cai, Bắc Kạn, Lạng Sơn, Tuyên Quang, Yên Bái, Điện Biên, Lai Châu, Sơn La. Khu vực này có địa hình bị chia cắt mạnh, độ dốc lớn; bên cạnh đó sự biến đổi tiêu cực của khí hậu cộng với các tác động của con người như việc khai thác rừng quá mức, các hoạt động xây dựng, san lấp đất, thủy điện,... đã ngăn cản, thay đổi dòng chảy tự nhiên làm gia tăng thiên tai, trong đó tập trung vào hai loại hình là lũ quét và sạt lở đất gây hậu quả ngày càng nghiêm trọng.

Theo báo điện tử Nhân Dân ngày 16/09/2020:

Tại các tỉnh miền núi phía Bắc, lũ quét, sạt lở đất do mua lón gây ra ngày càng nghiêm trọng, gây thiệt hại nặng nề về người và tài sản của nhân dân.

Theo báo cáo của Bộ Nông nghiệp và Phát triển nông thôn, những tháng đầu năm 2020, khu vục này đã xảy ra 92 trận dông, lốc, mua đá, mua lớn (nhiều hơn tổng số trận của cả năm 2019). Trong đó, có tám đọt muxa lón trên diện rộng, hai trận lũ quét, sạt lỏ đất gây thiệt hại nghiêm trọng về nhà ở, với khoảng 54 nghìn nhà sập, hu hại, tốc mái... Trong tuần tù 07/09/2020 đến 13/09/2020, mura lón trên diện rộng tại các tỉnh Lào Cai, Điện Biên và Hà Giang đã làm chín nguoòi chết, cùng nhiều nhà cửa, diện tích lúa, hoa màu bị hu hại; nhiều tuyến đuoòng bị ách tắc. Trên địa bàn TP Son La (Son La), ngày 8-8, xảy ra hiện tuợng đá lăn tại các bản Bôm Nam (xã Chiềng Đen), bản Púng (xã Chiềng Ngần), làm một nguoòi chết, một người bị thuoơng [9].

Trước tình hình thiên tai ngày càng cực đoan và khó lường, việc giáo dục về phòng tránh và ứng phó với lũ quét, sạt lở đất cho học sinh (HS) miền núi Bắc Bộ là vô cùng cần thiết. Học sinh Trung học phổ thông (THPT) là đối tượng đã phát triển tương đối 
toàn diện về cả thể chất và trí tuệ. Các em sẽ là chủ nhân của đất nước, là nhân tố quan trọng tác động đến quá trình làm chậm biến đổi khí hậu (BĐKH), ứng phó với thiên tai trong tương lai gần. Giáo dục về phòng tránh và ứng phó với lũ quét, sạt lở đất cho HS THPT Miền núi Bắc Bộ nhằm các mục đích: (1) Giáo dục hiểu biết về lũ quét, sạt lở đất; (2) Hướng dẫn các kỹ năng phát hiện sớm nguy cơ, phòng tránh lũ quét, sạt lở đất; (3) Tuyên truyền ý thức bảo vệ môi trường, việc phòng tránh và ứng phó với lũ quét, sạt lở đất đến cộng đồng. Các nội dung trên được thực hiện bằng hình thức tổ chức dạy học kết hợp (Blended learning) giữa tích hợp giáo dục trên lớp trong môn Địa lí và dạy học trực tuyến.

\section{PHƯƠNG PHÁP NGHIÊN CÚU}

Trong nghiên cứu về giáo dục phòng tránh và ứng phó với lũ quét, sạt lở đất cho HS miền núi Bắc Bộ, tác giả sử dụng các phương pháp sau:

- Phương pháp thu thập tổng hợp và phân tích tài liệu: Phương pháp này là quá trình thu thập tài liệu, xử lý thông tin qua hệ thống phân tích - tổng hợp, kết hợp giữa nội suy và ngoại suy. Nghiên cứu chủ yếu sử dụng tài liệu là các văn bản của Nhà nước về triển khai nhiệm vụ bảo vệ môi trường, phòng tránh thiên tai; các báo cáo khoa học và tài liệu hội thảo, các nghiên cứu về dạy học tích hợp, về dạy học kết hợp, về thực trạng dạy học ở khu vực vùng núi Bắc bộ, về các biện pháp phòng tránh lũ quét, sạt lở đất ở miền núi; các số liệu thống kê của các ban ngành và cơ quan; sách, báo, tạp chí, các tác phẩm đã xuất bản có liên quan đến nội dung của nghiên cứu. Tài liệu sau khi thu thập được sẽ tiến hành phân tích, xử lí phục vụ yêu cầu của nghiên cứu.

- Phương pháp điều tra, khảo sát thực tế ở các tỉnh miền núi Bắc Bộ có lũ quét, sạt lở đất xảy ra ở tần xuất cao như Lai Châu, Sơn La, Hà Giang, Bắc Kạn, Điện Biên,...nhằm thu được những thông tin và mức độ thiệt hại do lũ quét, sạt lở đất gây ra, về nhận thức của HS và giáo viên $(\mathrm{GV})$ về lũ quét, sạt lở đất và các biện pháp phòng tránh; điều tra, khảo sát về thực trạng dạy học nội dung phòng tránh và ứng phó với lũ quét, sạt lở đất ở nhà trường phổ thông.

Cụ thể về nội dung, hình thức, địa chỉ điều tra, khảo sát như sau:

+ Điều tra, khảo sát về nhận thức của $\mathrm{GV}$ và $\mathrm{HS}$ về BĐKH, lũ quét, sạt lở đất và cách phòng tránh. Hình thức bằng phiếu hỏi, lấy mẫu điểm ở các trường có nguy cơ cao xảy ra lũ quét, sạt lở đất: Trường THPT Na Rì tỉnh Bắc Kạn (10 phiếu GV, 50 phiếu HS),
Trường THPT huyện Điện Biên tỉnh Điện Biên (20 phiếu GV, 50 phiếu HS), Trường THPT Xín Mần huyện Xín Mần tỉnh Hà Giang (10 phiếu GV, 50 phiếu HS), Trường THPT Mường Than huyện Than Uyên tỉnh Lai Châu (10 phiếu GV, 50 phiếu HS).

+ Điều tra, khảo sát về hiện trạng cơ sở vật chất và việc ứng dụng CNTT\&TT trong dạy học ở trường THPT. Hình thức bằng phiếu hỏi, số lượng 10 phiếu; đối tượng khảo sát: Ban giám hiệu, GV một số trường THPT ở khu vực miền núi phía Bắc như Trường THPT Na Rì tỉnh Bắc Kạn, Trường THPT huyện Điện Biên tỉnh Điện Biên, Trường THPT Vị Xuyên huyện Vị Xuyên tỉnh Hà Giang, Trường THPT Mường Than huyện Than Uyên tỉnh Lai Châu.

+ Điều tra, khảo sát về năng lực sử dụng máy tính và khai thác thông tin trên Internet của $G V$ và $H S$; Hình thức bằng phiếu hỏi và trực tuyến; Số lượng 50 GV, 200 HS trường THPT khu vực miền núi Bắc Bộ: Trường THPT Na Rì tỉnh Bắc Kạn, Trường THPT huyện Điện Biên tỉnh Điện Biên, Trường THPT Vị Xuyên huyện Vị Xuyên tỉnh Hà Giang, Trường THPT Mường Than huyện Than Uyên tỉnh Lai Châu.

Quá trình điều tra kết hợp các câu hỏi định tính và định lượng, câu hỏi mở và câu hỏi lựa chọn để mở rộng nguồn thông tin thu thập và tạo cơ sở dữ liệu cho phân tích định tích so sánh, chắt lọc thông tin. Từ đó giúp định hướng cho việc tổ chức giáo dục hiệu quả nội dung phòng tránh và ứng phó với lũ quét, sạt lở đất ở nhà trường phổ thông miền núi.

- Phương pháp chuyên gia: Phương pháp chuyên gia là phương pháp thu thập, xử lí những đánh giá, dự báo bằng cách tập hợp và hỏi ý kiến các chuyên gia giỏi thuộc lĩnh vực giáo dục thông qua tiếp xúc, trao đổi.... Sử dụng phương pháp này giúp đưa ra được các kết luận, các kiến nghị, các quyết định và định hướng được các nội dung giáo dục phù hợp với đối tượng là HS phổ thông miền núi.

Trên cơ sở các kết quả điều tra, tác giả đã đánh giá và đưa ra giải pháp nhằm giáo dục hiệu quả nội dung phòng tránh và ứng phó với lũ quét, sạt lở đất cho HS THPT miền núi Bắc Bộ.

\section{KẾT QUẢ NGHIÊN CỨU}

\subsection{Một số khái niệm sử dụng trong nghiên cứu}

- Thiên tai:

Theo Khoản 1, Điều 1 của Luật sửa đổi, bổ sung một số điều của Luật phòng chống thiên tai của Quốc hội nước Cộng hòa XHCN Việt Nam (2020) quy định "Thiên tai là hiện tuợng tụ nhiên bất thuoơng có thể gây thiệt hại về người, tài sản, môi truờng, điều 
kiện sống và các hoạt động kinh tế - xã họi, bao gồm bão, áp thấp nhiệt đới, gió mạn trên biển, lốc, sét, mua lơn, lũ lũ quét, ngập lụt; sạt lở đất, sụt lún đất do mura lũ hoặc dòng chảy hoặc hạn hán; nuớc dâng, xâm nhập mặn, nắng nóng, hạn hán, cháy rùng do tụ nhiên, rét hại, mura đá, suoong mù, suoong muối, động đất, sóng thần và các loại thiên tai khác" [8].

- Lũ quét:

Theo từ điển bách khoa toàn thư mở Wikipedia "Lũ quét là một loại lũ có tốc độ mục nước lên rất nhanh khi một khối luợng nước khổng lồ di chuyển nhanh tù địa hình cao xuống thấp. Lũ quét thuờng xuất hiện ở nhũng nơ gần đồi núi, chảy tràn vào các thung lũng. Nó hình thành không chì tù nhũng cơn mua dông, bão tố, băng tuyết trên núi tan chảy một cách đột ngột; mà nó còn đến do con người: đó là khi đập ngăn nước hồ thủy điện bi võ, xả nuớc hồ thủy điện không đúng cách. Khi đó, một luợng nuoóc khổng lồ sẽ bất ngò đổ ập xuống với sức mạnh khủng khiếp. Sức tàn phá của nhũng trận lũ quét chịu ảnh hương của độ dốc địa hình và vật cản dòng chảy" [11].

- Sạt lở đất:

Cũng theo từ điển bách khoa toàn thư mở Wikipedia "Sạt lở đất là một hiện tuợng địa chất bao gồm một loạt các chuyển động của khối đất, nhu đá rơi, sụp suoòn núi và lũ bùn đá,... Do tác động dần dần của phong hóa (nước làm mềm đất) hay kiến tạo (khe nứt phát triển), thì liên kết của mái dốc vào khối chính không thắng nổi trọng lực, dẫn đến lở. Tại miền núi lở đất hay xảy ra vào mùa mura hay tuyết tan, và có thể tạo ra lũ bùn đá." [11]

- Dạy hoc tich hơp:

Theo Tài liệu tập huấn dạy học tích hợp ở truòng Trung hoc co sỏ, Trung hoc phổ thông của Bộ Giáo dục và Đào tạo (2014) "Dạy học tích hợp là định huớng dạy học giúp HS phát triển khả năng huy động tổng hợp kiến thức, kĩ năng,... thuộc nhiều lĩnh vực khác nhau để giải quyết có hiệu quả các vấn đề trong học tập và trong cuộc sống, đurợc thưc hiện ngay trong quá trình lĩnh hội tri thức và rèn luyện kĩ năng” [2].

\section{- Dạy học trục tuyến:}

Theo Đỗ Vũ Sơn (2016) "Dạy học trục tuyến là hìn thức dạy hoc có sủ dụng kết nối mạng Internet để thực hiện việc giảng dạy, tụ học, đọc, giao tiếp thông qua các hoạt động trục tuyến nhu bài giảng của $G V$, hoạt động mô phỏng, diễn đàn học tập, chat, eseminar, kiểm tra đánh giá,..." [6].

- Dạy học kết hợ:

Theo Đỗ Vũ Sơn (2016) "Dạy học kết hợp là sụ kết hợp nội dung, phuoong pháp, hình thức tổ chức giũa các cách dạy học khác nhau nhằm tối ưu hóa thế mạh, đảm bảo hiệu quả giáo dục đạt được là cao nhất'[6]. Trong nghiên cứu này tác giả sử dụng hình thức kết hợp giữa dạy học trực tuyến và dạy học giáp mặt trong giáo dục phòng tránh và ứng phó với lũ quét, sạt lở đất cho HS.

3.2. Giải pháp giáo dục về phòng tránh và ứng phó với lũ quét, sạt lở đất cho học sinh miền núi Bắc Bộ

3.2.1. Phân tích đối tự̣ng học sinh Trung học phổ thông miền núi Bắc Bộ

Sau khi tổng hợp, phân tích kết quả điều tra, khảo sát cho thấy thuận lợi và khó khăn trong triển khai giáo dục phòng tránh và ứng phó với lũ quét, sạt lở đất như sau:

- Thuận lợi: HS THPT miền núi Bắc Bộ đại đa số là người dân tộc thiểu số như Tày, Nùng, H'Mông, Dao, Mường, Khơ Mú, Thái, Hà Nhì,...chiếm hơn $70 \% /$ tổng số HS. Các em sống gần gũi với núi rừng, thiên nhiên nên kỹ năng sinh tồn và kỹ năng ứng xử với thiên nhiên có nhiều ưu điểm nổi trội. Bản tính các em rất thẳng thắn, ham hiểu biết, tin tưởng tuyệt đối vào $\mathrm{GV}$, nhà trường là điều kiện tốt cho giáo dục.

Hệ thống thông tin viễn thông, Internet được Chính phủ triển khai tới toàn thể lãnh thổ, $\mathrm{HS}$ và $\mathrm{GV}$ đều có điều kiện sử dụng thuận lợi. Các nhà trường THPT được trang bị phòng máy tính có kết nối Internet. Ví dụ ở bảng 1.1 là thống kê ở một số trường THPT thuộc tỉnh miền núi Bắc Kạn.

Bảng 1.1. Thống kê máy tính, máy chiếu tại các trường THPT tỉnh Bắc Kạn

\begin{tabular}{|c|l|c|c|c|}
\hline \multicolumn{1}{|c|}{ Tên trường } & \multicolumn{1}{|c|}{$\begin{array}{c}\text { Số máy } \\
\text { vi tính }\end{array}$} & Số máy chiếu & Mạng Internet \\
\hline 1 & THPT Chuyên & 40 & 08 & Tốt \\
\hline 2 & THPT Bắc Kạn & 35 & 06 & Tốt \\
\hline 3 & THPT Chợ Đồn & 32 & 05 & Tốt \\
\hline 4 & THPT Na Rì & 32 & 06 & Tốt \\
\hline
\end{tabular}




\begin{tabular}{|c|l|c|c|c|}
\hline Stt & \multicolumn{1}{|c|}{ Tên trường } & $\begin{array}{c}\text { Số máy } \\
\text { vi tính }\end{array}$ & Số máy chiếu & Mạng Internet \\
\hline 5 & THPT Ba Bế & 31 & 05 & Tốt \\
\hline 6 & THPT Chợ Mới & 30 & 04 & Tốt \\
\hline 7 & THPT Bộc Bố & 22 & 3 & Tốt \\
\hline 8 & THPT Quảng Khê & 20 & 3 & Tốt \\
\hline
\end{tabular}

Có 167/200 HS được khảo sát (chiếm 83,5 \%) sử dụng Smatphone nên việc học trực tuyến thuận lợi; 100\% HS THPT được dạy học cơ bản về máy tính, có thể sử dụng máy tính trong học trực tuyến.

$100 \%$ HS được khảo sát đều ý thức được sự cần thiết của việc bảo vệ môi trường, việc học các kỹ năng phòng tránh và ứng phó với lũ quét, sạt lở đất.

- Khó khăn:

Tuy nhận thức được mối hiểm họa từ lũ quét, sạt lở đất nhưng có đến 144/200 HS được khảo sát (chiếm $72 \%$ ) hiểu chưa chính xác hoặc chưa rõ ràng nguyên nhân gây ra lũ quét, lở đất; 161/200 HS được khảo sát (chiếm 80,5 \%) chưa thành thạo kỹ năng phát hiện sớm, kỹ năng phòng tránh và ứng phó với lũ quét, sạt lở đất.

Một số tập tục lạc hậu của dân tộc thiểu số như $\mathrm{du}$ canh $\mathrm{du} \mathrm{cu}$, phá rừng vẫn còn tồn tại ảnh hưởng đến nhận thức và hành vi của HS. Điều kiện kinh tế của gia đình HS còn rất khó khăn, sống chủ yếu dựa vào làm nông nghiệp trên đất đồi núi ít hiệu quả. Nhận thức, ý thức về việc bảo vệ môi trường cũng như kỹ năng phòng tránh thiên tai của $\mathrm{HS}$, người dân còn hạn chế.

Giờ học trên lớp là chương trình chính khóa đã được ấn định nên chỉ có một thời lượng nhỏ (khoảng 10 tiết học) cho nội dung giáo dục phòng tránh và giảm nhẹ thiên tai trong môn Địa lí THPT.

Với các phân tích trên cho thấy, việc nghiên cứu và đưa ra hình thức dạy học tích hợp trong môn Địa lí ở giờ học trên lớp và học tập trực tuyến trong thời gian ngoài giờ trên lớp về nội dung giáo dục phòng tránh và ứng phó với lũ quét, sạt lở đất là một giải pháp hợp lý để phát huy thuận lợi, khắc phục khó khăn.

3.2.2. Mục tiêu của giáo dục phòng tránh và ứng phó với lũ quét, sạt lở đất cho học sinh Trung học phổ thông miền núi Bắc bộ
- Mục tiêu chung: Bằng nội dung, phương pháp dạy học phù hợp nhằm giáo dục hiệu quả về phòng tránh và ứng phó với lũ quét, sạt lở đất cho HS THPT miền núi Bắc bộ, đồng thời tuyên truyền, giáo dục cộng đồng ý thức, trách nhiệm trong bảo vệ môi trường, phòng tránh lũ quét, sạt lở đất hiệu quả.

- Mục tiêu về kiến thức: Hiểu và trình bày được các kiến thức cơ bản, cần thiết về thiên tai, lũ quét, sạt lở đất, nguyên nhân, cách phát hiện sớm và các biện pháp phòng tránh hiệu quả.

- Mục tiêu về kĩ năng:

+ Kĩ năng hoạt động bảo vệ môi trường: giữ rừng, trồng cây xanh, giảm phát thải khí nhà kính,...

+ Kĩ năng nhận biết, phát hiện sớm về lũ quét, sạt lở đất.

+ Kĩ năng phòng tránh và giảm nhẹ tác hại do lũ quét, sạt lở đất gây ra; kĩ năng ứng phó hiệu quả khi lũ quét, sạt lở đất xảy ra; kĩ năng xử lý hậu quả do lũ quét, sạt lở đất.

+ Kĩ năng tuyên truyền, vận động cộng đồng tham gia bảo vệ môi trường, phòng tránh và ứng phó với lũ quét, sạt lở đất.

3.2.3. Nội dung giáo dục phòng tránh và ứng phó với lũ quét, sạt lở đất

* Nội dung giáo dục về lũ quét, sạt lơ đất và cách phòng tránh

Nội dung giáo dục tập trung vào một số vấn đề:

- Khái niệm về thiên tai, lũ quét, sạt lở đất.

- Các dấu hiệu nhận biết lũ quét, sạt lở đất:

+ Dấu hiệu nhận biết lũ quét: Khi có mưa liên tục nhiều ngày ở thượng lưu; nước sông suối từ trong chuyển màu đục do đất, đá từ thượng nguồn bị sạt lở, nước cuốn theo nên đây là dấu hiệu rất quan trọng; có tiếng động bất thường của đất đá, cây cối, xuất hiện âm thanh lạ trong lòng đất thì đó cũng là dấu hiệu có thể xảy ra lũ quét. 
+ Dấu hiệu nhận biết sạt lở đất: Những thay đổi xảy ra như các rãnh thoát nước mưa trên các sườn dốc (đặc biệt là những nơi mà dòng nước chảy tụ lại) xuất hiện dấu vết sạt lở, cây bị sạp... Cửa hoặc cửa sổ nhà ở bị kẹt, không thể mở ra; vết nứt mới xuất hiện trên tường, trần, gạch, nền. Xuất hiện các vết nứt mở rộng trên mặt đất hoặc trên lối đi, vỡ mạch nước ngầm, mặt đất có hiện tượng phồng rộp, nước phun ra từ mặt đất tại nhiều vị trí mới; hàng rào, tường chắn, cột điện, cây cối bị nghiêng hoặc di chuyển; nước chảy trên bề mặt đất đang từ trong chuyển sang đục,... Khi có tiếng rơi của đất đá với âm lượng tăng dần, mặt đất bắt đầu dịch chuyển xuống theo chiều dốc, các lớp đất thụt xuống, những âm thanh lạ, như tiếng cây gãy hoặc tảng đá va chạm với nhau tức là sạt lở đất bắt đầu xảy ra.

- Các nguyên nhân gây nên lũ quét, sạt lở đất:

+ Nguyên nhân trực tiếp: Mưa lớn liên tục trên địa hình dốc có kết cấu đất yếu; thiếu độ che phủ rừng, các tác động của con người lên địa hình như san lấp đất làm ảnh hưởng đến dòng chảy tự nhiên.

- Một số biện pháp nhằm xây dựng và bảo vệ môi trường sống, làm chậm quá trình $\mathrm{BĐKH}$, ứng phó với lũ quét, sạt lở đất.

* Nội dung thục hành nhận biết và úng phó với thiên tai vùng núi (lũ quét, sạt lở đất)

- Nhận biết, phát hiện sớm một số biểu hiện của lũ quét, sạt lở đất.

- Thực hành kỹ năng ứng phó khi xảy ra thiên tai; kỹ năng xử lý hậu quả của thiên tai.

- Thực hành kỹ năng vận động, tuyên truyền về ý thức bảo vệ môi trường, làm chậm quá trình $\mathrm{BĐKH}$, phòng tránh thiên tai.

\subsubsection{Giải pháp giáo dục}

3.2.4.1. Tích hợp nội dung về phòng tránh và ưng phó với lũ quét, sạt lơ đất trong môn Địa lí

Theo Chuong trình giáo dục phổ thông môn Địa lí của Bộ Giáo dục và Đào tạo (2018), một trong những quan điểm xây dựng chương trình là: "Chương trình môn Địa lí chú trọng tích hợp, thực hành, gắn nội dung giáo dục của môn học với thực tiễn nhằm rèn luyện cho HS kĩ năng vận dụng kiến thức địa lí vào việc tìm hiểu và giải quyết ở mức độ nhất định một số vấn đề của thực tiễn, đáp ứng đòi hỏi của cuộc sống.... Chương trình xác định thực hành, luyện tập, vận dụng là nội dung quan trọng, đồng thời là công cụ thiết thực, hiệu quả để phát triển năng lực của HS. Nội dung này chú trọng việc vận dụng kiến thức địa lí vào thực tiễn nhằm góp phần phát triển các năng lực đặc thù của môn học" [4].

Theo đó, chương trình cũng đề ra các chuyên đề học tập gắn với việc giáo dục bảo vệ môi trường và phòng chống thiên tai, đó là:

- Chuyên đề Biến đổi khi hậu (Địa lí lớp 10):

+ Nội dung chuyên đề: Khái niệm, biểu hiện, nguyên nhân của $\mathrm{B} Đ K H$; các tác động của $\mathrm{B} Đ K H$ và hậu quả; .

+ Yêu cầu cần đạt: Trình bày được khái niệm, các biểu hiện của $\mathrm{BĐKH}$; giải thích được nguyên nhân của $\mathrm{BĐKH;} \mathrm{phân} \mathrm{tích} \mathrm{được} \mathrm{các} \mathrm{tác} \mathrm{động} \mathrm{của} \mathrm{B} Đ K H$ và hậu quả trên phạm vi toàn cầu; giải thích được tầm quan trọng và sự cấp bách của ; hệ thống hoá được các nhóm giải pháp .

- Chuyên đề: Thiên tai và biện pháp phòng chống (Địa lí lớp 12):

+ Nội dung chuyên đề: Những vấn đề chung; một số thiên tai, nguyên nhân, hậu quả, biện pháp phòng chống.

+ Yêu cầu cần đạt: Trình bày được quan niệm, đặc điểm, nguyên nhân, phân loại thiên tai; Trình bày được một số thiên tai và nơi thường xảy ra (bão, lũ lụt, hạn hán, các thiên tai khác); phân tích được nguyên nhân, hậu quả của mỗi loại và xác định được các biện pháp phòng chống; liên hệ, tìm hiểu được về một thiên tai cụ thể tại địa phương (hiện trạng, nguyên nhân, hậu quả, giải pháp); thu thập được tranh ảnh, số liệu, video clip,... để trưng bày một số chủ đề về thiên tai; viết được đoạn văn ngắn tuyên truyền mọi người trong cộng đồng về thiên tai và các biện pháp phòng chống [4].

Ngoài các chuyên đề được đưa vào chương trình chính khóa như đã nêu, việc giáo dục nội dung phòng tránh và ứng phó với lũ quét, sạt lở đất còn có thể tích hợp trong quá trình dạy học môn Địa lí. Ví dụ: Bảng 2 là nội dung, địa chỉ và hình thức tích hợp trong chương trình Địa lí lớp 12 THPT: 
Bảng 2. Nội dung, địa chỉ, hình thức tích hợp

\begin{tabular}{|c|c|c|c|}
\hline Bài/tên bài & Nội dung tích họ̣p & Địa chỉ tích hợp & $\begin{array}{l}\text { Hình thức } \\
\text { tích hợp }\end{array}$ \\
\hline $\begin{array}{l}\text { Bài 7. Đất nước } \\
\text { nhiều đồi núi }\end{array}$ & $\begin{array}{l}\text { Khu vực đồi núi : BĐKH } \rightarrow \text { tăng thiên tai } \\
\text { trong điều kiện địa hình chia cắt mạnh, độ } \\
\text { dốc lớn } \rightarrow \text { hậu quả càng nặng nề. } \\
\text { - Khu vực đồng bằng : BĐKH } \rightarrow \text { nước } \\
\text { biển dâng } \rightarrow \text { gây ngập úng và xâm nhập } \\
\text { mặn trên diện rộng. }\end{array}$ & $\begin{array}{l}\text { Mục 3: Thế mạnh và hạn } \\
\text { chế về tự nhiên của các } \\
\text { khu vực đồi núi và đồng } \\
\text { bằng đối với phát triển kinh } \\
\text { tế xã hội }\end{array}$ & Liên hệ \\
\hline $\begin{array}{l}\text { Bài } 11+12 . \text { Thiên } \\
\text { nhiên phân hóa đa } \\
\text { dạng }\end{array}$ & $\begin{array}{l}\text { Ở mỗi miền địa lí tự nhiên cần có các biện } \\
\text { pháp giảm nhẹ tác động của thiên tai và thích } \\
\text { ứng với những thách thức ngày càng tăng do } \\
\text { BĐKH. }\end{array}$ & 4. Các miền địa lí tự nhiên & Liên hệ \\
\hline $\begin{array}{l}\text { Bài } 14 \text {. Sử dụng và } \\
\text { bảo vệ tài nguyên } \\
\text { thiên nhiên }\end{array}$ & $\begin{array}{l}\text { - Sự suy giảm quá mức tài nguyên rừng và } \\
\text { các hệ sinh thái khác làm BĐKH. } \\
\text { - Tác động của } \mathrm{BĐKH} \mathrm{đến} \mathrm{tài} \mathrm{nguyên} \\
\text { nước. }\end{array}$ & $\begin{array}{l}\text { 1. Sử dụng và bảo vệ tài } \\
\text { nguyên sinh vật } \\
\text { 3. Sử dụng và bảo vệ các } \\
\text { tài nguyên khác }\end{array}$ & Liên hệ \\
\hline $\begin{array}{l}\text { Bài } 15 \text {. Bảo vệ môi } \\
\text { trường và phòng } \\
\text { chống thiên tai }\end{array}$ & $\begin{array}{l}\text { - Sự biến đổi môi trường sẽ dẫn tới sự } \\
\text { BĐKH và ngược lại. } \\
\text { - Sự BĐKH sẽ làm tăng hậu quả của } \\
\text { thiên tai. } \\
\text { - Cần các biện pháp giảm nhẹ và thích } \\
\text { ứng với các thiên tai: Bão, lụt, hạn hán. } \\
\text { - Thực hiện các nhiệm vụ của chiến lược } \\
\text { là góp phần hạn chế BĐKH. }\end{array}$ & $\begin{array}{l}\text { 1. Bảo vệ môi trường. } \\
\text { 2. Một số thiên tai chủ yếu } \\
\text { và biện pháp phòng chống } \\
\text { 3. Chiến lược quốc gia về } \\
\text { bảo vệ tài nguyên và môi } \\
\text { trường }\end{array}$ & Kết hợp \\
\hline Bài 18. Đô thị hóa. & $\begin{array}{l}\text { Đô thị phát triển mạnh mẽ } \rightarrow \text { gia tăng hoạt } \\
\text { động giao thông vận tải... } \rightarrow \text { ô nhiễm } \\
\text { không khí } \rightarrow \text { BĐKH. } \\
\text { Các đô thị ven biển chịu tác động lớn } \\
\text { của BĐKH. }\end{array}$ & $\begin{array}{l}\text { 3. Ảnh hưởng của đô thị } \\
\text { hóa đến phát triển kinh tế - } \\
\text { xã hội. }\end{array}$ & Liên hệ \\
\hline $\begin{array}{l}\text { Bài 30. Vấn đề phát } \\
\text { triển ngành giao } \\
\text { thông vận tải và } \\
\text { thông tin liên lạc. }\end{array}$ & $\begin{array}{l}\text { Sự gia tăng mạnh mẽ của các phương tiện } \\
\text { vận tải dẫn tới ô nhiễm không khí góp phần } \\
\text { dẫn đến } B Đ K H .\end{array}$ & 1. Giao thông vận tải. & Liên hệ \\
\hline $\begin{array}{l}\text { Bài 32. Vấn đề khai } \\
\text { thác thế mạnh ở } \\
\text { Trung du và miền núi } \\
\text { Bắc Bộ. }\end{array}$ & $\begin{array}{l}\text { - Quá trình xây dựng và các hoạt động } \\
\text { của các công trình thủy điện lớn chịu tác } \\
\text { động lớn của BĐKH và ngược lại. } \\
\text { - Sự gia tăng các thiên tai : xói mòn, trượt lở } \\
\text { đất, rét đậm, rét hại... do BĐKH ảnh hưởng } \\
\text { tới năng suất cây trồng, vật nuôi. } \\
\text { - Cần chủ động ứng phó với các tác động của } \\
\text { BĐKH trong vùng. }\end{array}$ & $\begin{array}{l}\text { 2. Khai thác, chế biến khoáng } \\
\text { sản và thủy điện } \\
\text { 3. Trồng và chế biến cây } \\
\text { công nghiệp, cây dược liệu, } \\
\text { rau quả cận nhiệt đới và ôn } \\
\text { đới } \\
\text { 4. Chăn nuôi gia súc }\end{array}$ & Liên hệ \\
\hline $\begin{array}{l}\text { Bài } 44 \text { - 45. Tìm hiểu } \\
\text { địa lí tỉnh thành phố. }\end{array}$ & $\begin{array}{l}\text { Tích hợp lý thuyết và kĩ năng về các } \\
\text { biện pháp phòng tránh, ứng phó với lũ } \\
\text { quét, sạt lở đất ở các địa phương vùng } \\
\text { núi Bắc Bộ. }\end{array}$ & $\begin{array}{l}\text { Tổ chức hoạt động trải } \\
\text { nghiệm trong phòng và } \\
\text { ngoài thực địa }\end{array}$ & Kết hợp \\
\hline
\end{tabular}


Biện pháp tổ chức trong quá trình dạy học giáp mặt là:

- Lồng ghép kiến thức về giáo dục phòng tránh và ứng phó với lũ quét, sạt lở đất trong bài học môn Địa lí trên lớp (xem bảng 2).

- Hướng dẫn HS sử dụng module trong học tập trực tuyến về giáo dục phòng tránh và ứng phó với lũ quét, sạt lở đất; tổ chức kết hợp nội dung dạy giáp mặt và dạy học online.

- Tổ chức một số hoạt động trải nghiệm trong quá trình dạy học trên lớp như: hoạt động thuyết trình tuyên truyền về bảo vệ môi trường; thi tìm hiểu về lũ quét, sạt lở đất và cách phòng tránh; tổ chức "trò chơi" về ứng phó với lũ quét, sạt lở đất;:...Các hoạt động này cần có nội dung thiết thực, hình thức lôi cuốn, dễ thực hiện, nhớ lâu.

- Tổ chức khảo sát ngoài thực địa những khu vực đã xảy ra lũ quét, sạt lở đất ở địa phương; tìm hiểu nguyên nhân và hậu quả; tìm hiểu những khu vực có nguy cơ cao về lũ quét, sạt lở đất; tìm hiểu các biện pháp phòng tránh và ứng phó; tiếp cận người dân và thực hành tuyên truyền.

Việc kiểm tra, đánh giá quá trình học môn Địa lí cần có nội dung về giáo dục phòng tránh và ứng phó với lũ quét, sạt lở đất.

3.2.4.2. Dạy học trục tuyến về giáo duc phòng tránh và úng phó với lũ quét, sạt lở đất
Khóa học trực tuyến Giáo dục phòng tránh và úng phó với lu quét, sạt lở đất được xây dựng trên nền tảng của hệ thống Learning Content Management System (LCMS), địa chỉ http://dovuson.loptructuyen.com/, gồm các hoạt động chính:

- Quản lý các khoá học trực tuyến và quản lý NH.

- Quản lý quá trình học tập của NH và quản lý nội dung dạy học của các khoá học.

- Quản lý NH, đảm bảo việc đăng ký, kết nạp và theo dõi quá trình tích luỹ kiến thức của $\mathrm{NH}$.

- Báo cáo kết quả học tập của NH và tích hợp với hệ thống quản lý đào tạo của nhà trường.

- Tích hợp các dịch vụ cộng tác hỗ trợ trong quá trình trao đổi giữa $\mathrm{GV}$ với $\mathrm{NH}$, giữa $\mathrm{NH}$ với $\mathrm{NH}$. Các dịch vụ này bao gồm: giao nhiệm vụ tới $\mathrm{NH}$, thảo luận khoá học, trao đổi thông điệp điện tử, e-mail, thông báo mới, lịch học...

- Các nội dung về giáo dục phòng tránh và ứng phó với lũ quét, sạt lở đất được đưa khóa học ở dạng lớp học online, text, videos, PowerPoint, ảnh,...dễ tiếp thu, hấp dẫn và phù hợp với nhiều lứa tuổi người học; phần tài liệu tham khảo rất phong phú, cập nhật; phần kiểm tra, đánh giá với nhiều loại hình như trắc nghiệm khách quan, tự luận và có kết quả phản hồi ngay sau khi hoàn thành bài kiểm tra cũng như những nhận xét giúp cho người học tự điều chỉnh kiến thức; phần diễn đàn, thảo luận, lớp học online giúp cho người học được tiếp xúc, trao đổi với nhiều chuyên gia. Hình 1. là giao diện của khóa học trực tuyến giáo dục phòng tránh và ứng phó với lũ quét, sạt lở đất (xem hình 1 , hình 2 ).

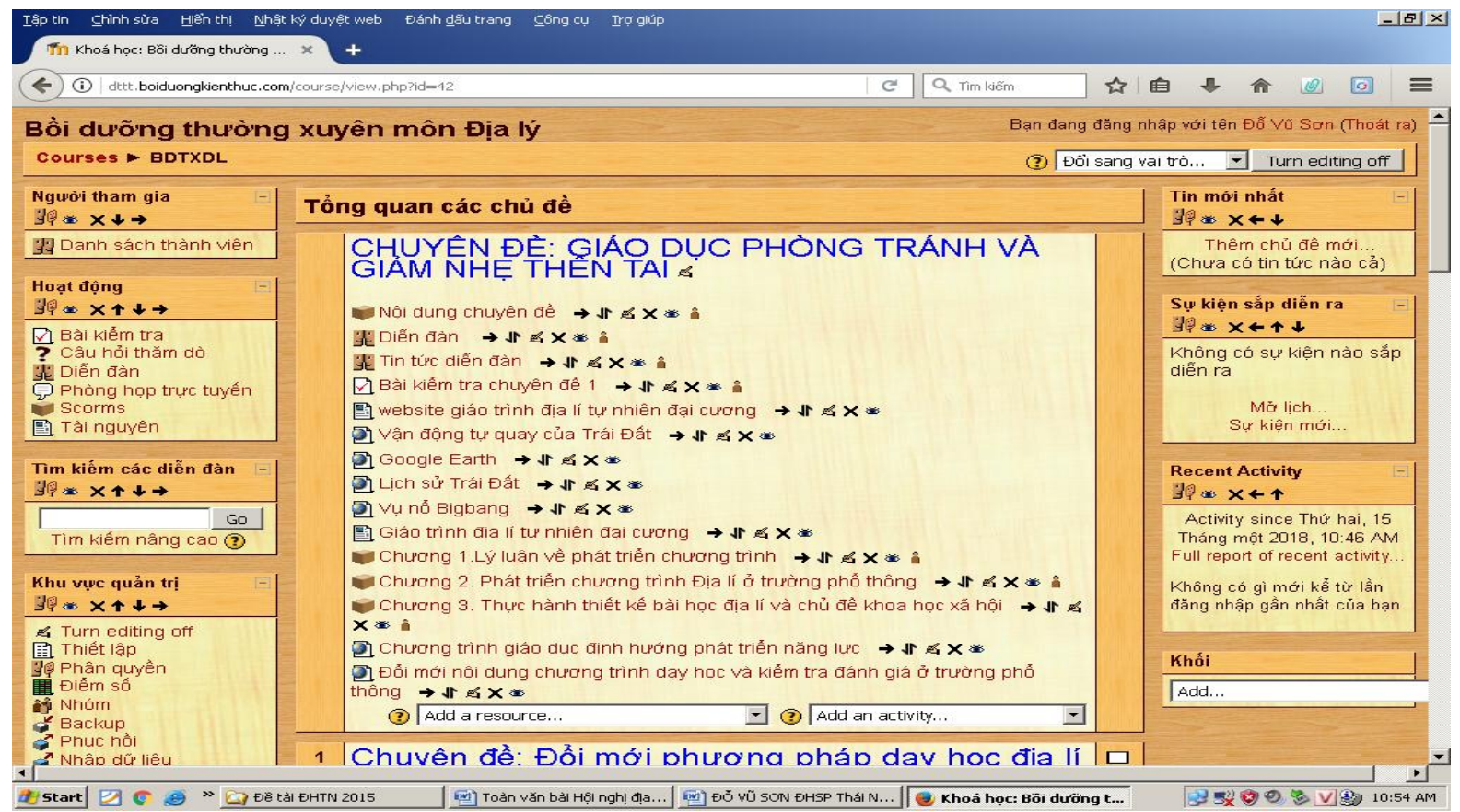

Hình 1. Giao diện của khóa học giáo dục phòng tránh và ứng phó với lũ quét, sạt lở đất 


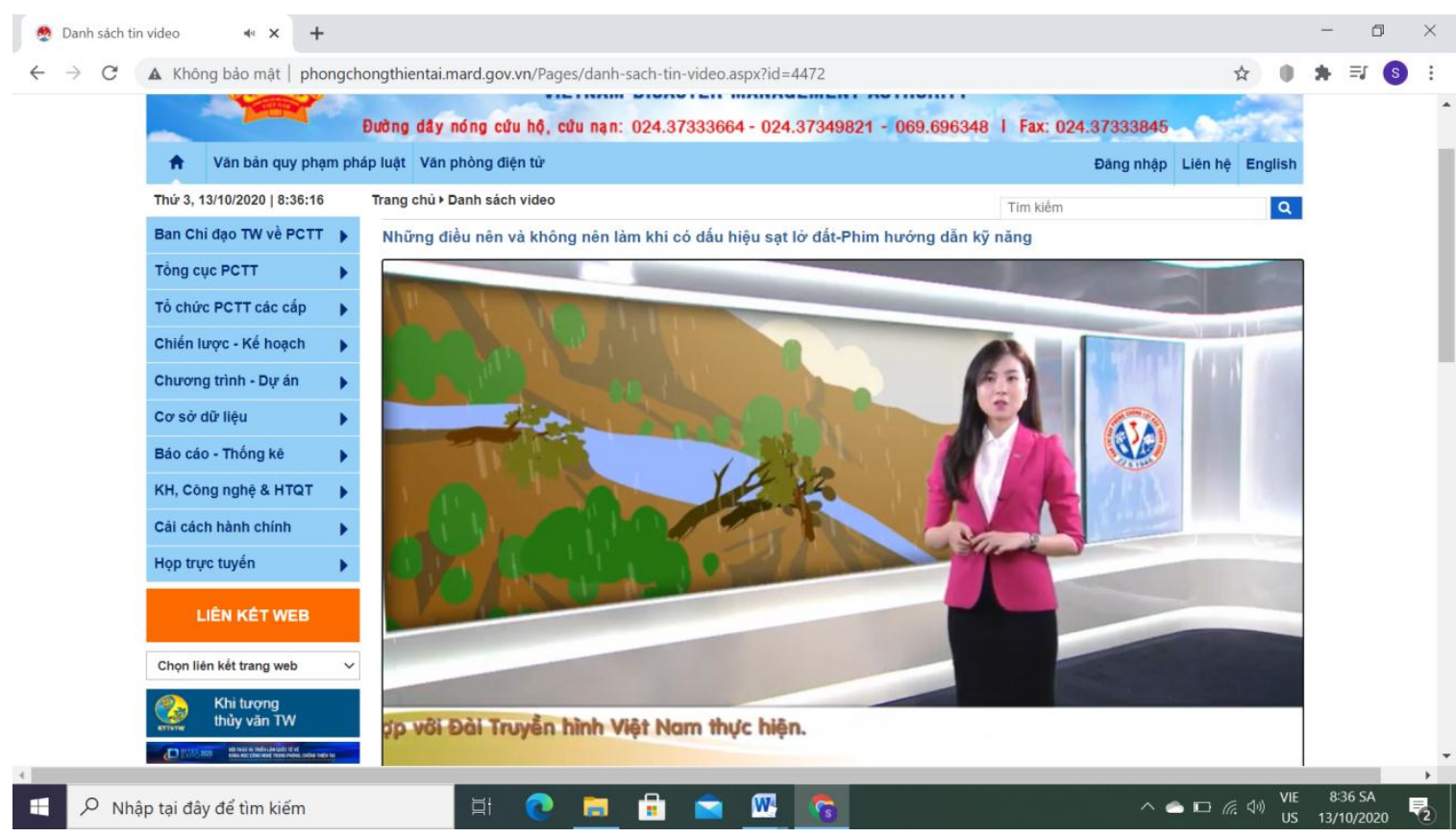

Hình 2. Videos giáo dục phòng tránh và ứng phó với lũ quét, sạt lở đất được tích hợp trong khóa học trực tuyến [Ảnh chụp màn hình - Nguồn: http://phongchongthientai.mard.gov.vn/Pages/danh-sach-tinvideo.aspx?id=4472]

\subsubsection{Tổ chức dạy học kết hợp}

Giáo dục phòng tránh và ứng phó với lũ quét, sạt lở đất cho HS miền núi được tổ chức theo hình thức Blended - learning, có nghĩa là một phần nội dung được dạy học trên lớp theo phương pháp tích hợp trong môn học Địa lí, một phần nội dung được dạy online với thời gian ngoài giờ lên lớp.

Việc tổ chức dạy học được tiến hành song song giữa dạy học trên lớp với dạy học online

Các nội dung dạy học trên lớp trong chương trình chính khóa được tích hợp trong môn Địa lí. Các nội dung còn lại được tổ chức theo hình thức online. HS theo hướng dẫn trên phần mềm sẽ tự nghiên cứu và thực hiện các hoạt động học tập.

Một số phương pháp dạy học kết hợp mà nhóm nghiên cứu đã thực hiện hiệu quả:

\section{* Day hoc hơp tác}

Dạy học hợp tác là phương pháp dạy học trong đó các nhóm người học cùng giải quyết nhiệm vụ học tập cụ thể mà $\mathrm{GV}$ đưa ra, từ đó rút ra kiến thức. Đòi hỏi kết hợp nhiều yếu tố: trách nhiệm cá nhân, phân chia nhóm, kĩ năng giao tiếp, đánh giá quá trình hợp tác, tiến hành các hoạt động tương tác,...

Ví dụ: Để tìm hiểu về các loại hình thiên tai ở vùng núi nơi HS cư trú, GV chia HS thành nhiều nhóm với nhiệm vụ của mỗi nhóm tìm hiểu một nội dung về một loại hình thiên tai có thể xảy ra ở khu vực này. Các hoạt động chia nhóm, giao nhiệm vụ được thực hiện bằng hinh thức trực tuyến. HS tìm hiểu các nội dung trên Internet và qua khảo sát thực địa. Sau đó, tổ chức thảo luận, kết luận, đánh giá kết quả được thực hiện trên lớp hoặc qua phòng họp online.

\section{* Dạy học phân hoá}

Dạy học phân hoá xuất phát từ sự biện chứng của thống nhất và phân hoá, từ yêu cầu đảm bảo thực hiện tốt các mục đích dạy học đối với người học, đồng thời khuyến khích phát triển tối đa và tối ưu những khả năng của cá nhân. Dựa vào năng lực, GV sẽ phân loại HS thành các nhóm. Sau đó đưa ra các bài tập, các chủ đề thảo luận phù hợp cho từng nhóm, đồng thời tổ chức tác động qua lại trao đổi, tự đánh giá. Trên cơ sở đó, hình thành thói quen tự đánh giá, tự điều chỉnh cho HS.

Ví dụ, để chuẩn bị tổ chức hoạt động về giáo dục phòng tránh và ứng phó với lũ quét, sạt lở đất, có thể phân chia các nhóm HS theo khả năng:

Nhóm 1: Có khả năng thuyết trình về vấn đề phòng tránh và ứng phó với lũ quét, sạt lở đất.

Nhóm 2: Có khả năng sử dụng bản đồ, GIS trong nghiên cứu các thiên tai trong khu vực.

Nhóm 3: Có khả năng hướng dẫn các kĩ năng phát hiện sớm, phòng tránh và ứng phó với lũ quét, sạt lở đất. 
Nhóm 4: Có khả năng tuyên truyền, vận động người dân.

Tương đương với 4 nhóm HS thiết kế những nội dung theo ưu thế của từng nhóm. Đồng thời huy động HS của các nhóm tham gia hoạt động chéo để giúp đỡ các nhóm khác hoàn thành tốt nội dung học. Các nội dung người học có thể tự tiếp thu được thực hiện bằng dạy học trực tuyến, các hoạt động phối hợp nhóm được thực hiện trực tiếp.

\section{* Day hoc chuoong trình hoá}

Chương trình hóa thực chất là chia nhỏ nội dung bài học làm nhiều đơn vị có liên quan đến nhau, việc thực hiện đơn vị tiếp theo phụ thuộc vào kết quả, chất lượng lĩnh hội kiến thức của đơn vị trước. Việc dạy học chương trình hóa được lập trình hoàn toàn tự động thông qua các hình thức như nêu vấn đề, diễn giải, minh họa, kiểm tra, củng cố ôn tập,... được sắp xếp theo một trình tự nhất định. HS theo hướng dẫn trên khóa học trực tuyến chủ động, độc lập thực hiện việc học tập. Quá trình tự học chính là quá trình HS đạng lĩnh hội kiến thức, nếu đã hiểu (trả lời đúng) thì đi tiếp, nếu chưa hiểu (trả lời sai) thì quay lại đơn vị học tập trước hoặc từ đầu. Dạy học chương trình hóa không tốn thời gian học trên lớp mà vẫn đạt hiệu quả học tập, tăng sự thích thú cho HS.

\subsection{Kinh nghiệm trong giáo dục phòng tránh} và ứng phó với lũ quét, sạt lở đất cho học sinh Trung học phổ thông miền núi Bắc Bộ

Thông qua nghiên cứu, tác giả đã rút ra được một số kinh nghiệm có thể chia sẻ cho các nhà quản lý, các cơ sở giáo dục, GV phổ thông ở những vùng lãnh thổ có điều kiện tương tự như của miền núi Bắc Bộ để tham khảo như sau:

- Việc giáo dục phòng tránh và ứng phó với lũ quét, sạt lở đất cho HS miền núi cần được chỉ đạo nhất quán và có chương trình hành động cụ thể của các cấp quản lý, các cơ sở giáo dục từ Trung ương cho đến địa phương. Bộ Giáo dục và Đào tạo năm 2014 đã triển khai đề án "Thông tin, tuyên truyền về phòng, chống thiên tai trong trường học giai đoạn 2013-2020" với mục tiêu: “Thông tin, tuyên truyền nâng cao nhận thức và kĩ năng về phòng, chống thiên tai cho trẻ em, HS, học viên, cán bộ, $G V$, giảng viên, nhân viên của ngành Giáo dục và cha mẹ $H S$, cộng đồng” [3]. Theo đó, các cơ quan quản lý giáo dục, các nhà trường, cơ sở giáo dục miền núi cần xây dựng chương trình hành động cụ thể cho từng năm học về giáo dục phòng tránh và giảm nhẹ thiên tai, trong đó có phòng tránh và ứng phó với lũ quét, sạt lở đất.

- Sử dụng kết hợp nhiều hình thức, thể loại, phương pháp giáo dục nhằm nâng cao nhận thức của toàn dân, trong đó có HS THPT về bảo vệ môi trường, phòng tránh và ứng phó với lũ quét, sạt lở đất như giáo dục trong và ngoài nhà trường gắn với các hoạt động thực hành, thực tế, rèn luyện kỹ năng; giáo dục ở cộng đồng; giáo dục thông qua phương tiện thông tin, đại chúng như mạng xã hội, truyền hình, tranh cổ động,... Các hình thức, phương pháp giáo dục phải đơn giản, dễ hiểu, hấp dẫn, phù hợp với điều kiện tự nhiên, kinh tế xã hội, phong tục của vùng núi, dân tộc thiểu số.

- Trong nhà trường phổ thông, việc tổ chức dạy học về giáo dục phòng tránh và ứng phó với lũ quét, sạt lở đất cho HS miền núi cần phải xét đến điều kiện, hoàn cảnh, năng lực thực tế của từng nhà trường sao cho phù hợp. Cần tận dụng tối đa thế mạnh của Công nghệ thông tin và truyền thông, đặc biệt là dạy hoc trực tuyến, dạy học kết hợp (Blended learning) trong giáo dục, tuyên truyền nội dung này. Nội dung giáo dục cần gắn với thực tế địa phương nơi trường đóng; hình thức tổ chức đơn giản, dễ thực hiện, gần gũi, lôi cuốn, dễ hiểu. Tổ chức các hoạt động chơi mà học như tham quan thực tế tìm hiểu về lũ quét, sạt lở đất đã xảy ra ở địa phương, hoạt động câu lạc bộ tuyên truyền về bảo vệ môi trường, hoạt động thực hành về kỹ năng ứng phó với lũ quét, sạt lở đất,...Cần xây dựng kế hoạch học tập chi tiết, kết hợp với các môn học chính khóa và thời gian ngoài giờ lên lớp một cách hợp lý, không làm ảnh hưởng đến hoạt động dạy học ở nhà trường và thời gian nghỉ ngơi, vui chơi của HS.

\section{Kết luận}

Giáo dục phòng tránh và ứng phó với lũ quét, sạt lở đất cho $\mathrm{HS}$ vùng núi là hết sức cần thiết vì tạo ra một thế hệ con người hiểu biết, ứng xử có trách nhiệm với thiên nhiên, có kỹ năng tốt trong phòng chống thiên tai.

Tác giả đã sử dụng các phương pháp: tổng hợp và phân tích tài liệu, điều tra khảo sát thực tế, phương pháp chuyên gia, phương pháp thực nghiệm sư phạm, phương pháp toán thống kê để thực hiện các nghiên cứu gồm: điều tra khảo sát tại các trường THPT miền núi về khả năng giáo dục về phòng tránh và ứng phó với lũ quét, sạt lở đất; tích hợp nội dung giáo dục phòng tránh và ứng phó với lũ quét, sạt lở đất trong môn Địa lí; xây dựng và sử dụng khóa học trực tuyến về giáo dục phòng tránh và ứng phó với lũ quét, sạt 
lở đất; tổ chức dạy học theo hình thức kết hợp giữa dạy học trên lớp với dạy học trực tuyến. Kết quả của nghiên cứu là giáo dục được ý thức bảo vệ môi trường, kỹ năng tự bảo vệ trước thảm họa thiên nhiên cho HS Trung học phổ thông miền núi, thông qua HS để tuyên truyền sâu rộng trong toàn dân ý thức, trách nhiệm bảo vệ môi trường.

Với giải pháp và kinh nghiệm trong giáo dục phòng tránh và ứng phó với lũ quét, sạt lở đất cho HS Trung học phổ thông miền núi Bắc Bộ là kinh nghiệm cho các vùng lãnh thổ, quốc gia khác trên thế giới có điều kiện, hoàn cảnh tương tự như ở .

Nghiên cứu này được tài trọ bởi Bộ Giáo duc và Đào tạo, trong đề tài Mã số: B2020-TNA-10.

\section{References}

1. Ministry of Education and Training (2012) Teaching and Learning Guidelines forNatural Disaster Risk Reduction, Hanoi.

2. Ministry of Education and Training (2014), Training materials for integrated teaching in junior high schools, high schools, Pedagogical University Publishing House, Hanoi.

3. Ministry of Education and Training (2014), Project "Information, propaganda on and prevention and control of natural disasters in schools in the period 2013-2020", Hanoi.
4. Ministry of Education and Training (2018), General Education Program - Master Program, Hanoi.

5. Government of the Socialist Republic of Vietnam (2008), The National Target Program to Combat against Climate Change, Hanoi

6. Do Vu Son (2016), Online teaching textbook of Geography. Thai Nguyen University Publishing House, Thai Nguyen.

7. Le Thong (Editor-in-chief) (2016), Geography Textbook 8,9,10. Education Publishing House, Hanoi.

8. National Assembly of the Socialist Republic of Vietnam (2020) Law amending and supplementing a number of articles of the Law on natural disaster prevention and the Law on dikes, No. 60/2020 / QH14 dated 17/06/2020, Hanoi.

9. https://nhandan.com.vn/cung-suy-ngam/chudong-de-phong-mua-lon-gay-lu-quet-sat-lo-dat$\underline{612539 /}$

10. https://www.dkn.tv/khoa-hoc-cong-nghe/luquet-va-lu-ong-o-tay-bac-khac-nhau-nhu-thenao.html

11. https://vi.wikipedia.org/wiki/Tai biến tự_nhiên

\section{EDUCATION ON FLASH FLOOD PREVENTION AND RESPONSE, LANDSLIDE FOR STUDENTS OF HIGH SCHOOL IN THE NORTHERN MOUNTAINOUS REGION - SOLUTION AND EXPERIENCE}

\section{Article info}

Recieved:

27/8/2020

Accepted:

20/9/2020

Keywords: prevention and response to flash floods, landslides, integrated teaching, combined teaching, high school students, Northern mountainous areas.

\begin{abstract}
Flash floods and landslides in the Northern mountainous region have caused increasingly serious and unpredictable consequences. The study of reasonable measures to educate mountainous students about the prevention and response to flash floods and landslides for is extremely necessary and urgent.

The author has used the methods: document synthesis and analysis, actual investigation, expert method, combined teaching method to study the ability and implement the education of environment protection consciousness, self-protection skills against natural disasters for high school students in mountainous areas, through which propaganda deeply and widely awareness and responsibility of environmental protection to the society. The problems drawn from the research process are valuable experience for organizing the education of students in other areas.
\end{abstract}

